\title{
EL PENSAMIENTO EUGÉNICO DE MARAÑÓN
}

\author{
Alejandra Ferrándiz y Enrique Lafuente \\ UNED, Senda del Rey s/n. - 28071 Madrid (España)
}

\section{RESUMEN}

A finales de 1920 y comienzos de 1930 tiene lugar uno de los primeros intentos de institucionalización de la Eugenesia en España. Son éstos también los años en que Marañón, por entonces una de las figuras públicas de mayor relieve y prestigio de todo el país, escribe sobre el tema. Su gran reputación no sólo como médico y hombre de ciencia, sino también como escritor y conferenciante sobre asuntos de amplio alcance social, dotó a sus escritos de una eficacia divulgadora incomparable, lo que hace enormemente significativa su defensa del ideal eugénico.

A pesar de la importancia que atribuyó siempre a la Eugenesia, Marañón no llegó a escribir nunca un tratado sobre el tema. Pero los escritos dispersos en que se ocupa de él contienen ideas que, a nuestro juicio, componen una auténtica doctrina eugénica. En este trabajo hemos pretendido reconstruir la figura de semejante doctrina, subrayando las principales líneas de problemas (biológicos, económicos, políticos, educativos y morales) que plantea para Marañón la cuestión eugénica. Intentamos de este modo recuperar una pieza que nos parece clave para comprender cabalmente el desarrollo de las ideas eugénicas en España.

\section{SUMMARY}

Athough eugenic ideas were by no means alien to Spanish thought before the 20th century, it is only by the end of the 1920s and the beginning of the 1930s that the first steps towards an institutionalization of Eugenics in Spain were actually taken. In this period, Dr. Marañon produced a number of interesting writings, mostly of a minor or occasional nature, on Eugenic subjects. Marañon was by then one of the leading intellectuals of his generation. His great reputation as a physician and as a man of science was only equal to his wide acknowledgement as a writer on general social issues, which makes his contribution to Eugenics particularly significant.

In spite of the attention always paid by Marañón to Eugenic issues, he never published a proper treatise on the subject. His views must therefore be gathered from very scattered sources. The aim of this paper is to accomplish such a task, and thus draw an outline of Marañón's eugenic program by emphasizing those aspects (biological, economic, political, educational and moral) he mainly dealt with. It is there thereby sought to unearth a key contribution to the development of eugenic ideas in early 20 th century.

El día 2 de febrero de 1928 se inauguraba en Madrid, en la Facultad de Medicina de la Universidad Central, el Primer Curso Eugénico Español, con el que se pretendía dar respuesta al creciente interés que las cuestiones eugénicas venían suscitando en la 


\section{ALEJANDRA FERRÁNDIZ Y ENRIQUE LAFUENTE}

sociedad española desde comienzos de siglo ${ }^{1}$. El Curso, empero, contó desde el principio con la oposición decidida de las autoridaades eclesiásticas, que impidieron participar en él a quienes podían haber representado el punto de vista de la Iglesia sobre dichas cuestiones (los sacerdotes P. Laburu y P. Sureda) y propiciaron, en cambio, una feroz campaña de prensa (en los diarios El Debate y El Siglo Futuro) desacreditando el Curso y a sus conferenciantes. La presión ejercida sobre el régimen de Primo de Rivera culminó con la suspensión oficial del Curso por un Real Decreto ( 2 de marzo de 1928) en que se lo llegaba a calificar de «regodeo pornográfico ${ }^{2} »$.

Este gesto de prepotencia de la Dictadura fue probablemente más beneficioso que perjudicial para la difusión de las ideas eugénicas en España: a partir de ese momento, el panorama editorial español se puebla en poco tiempo de publicaciones de autores nacionales y extranjeros sobre ellas ${ }^{3}$. Marañón mismo se referirá al «éxito magnífico» que supuso esta interrupción forzosa, porque a su entender ella significaba que «la semilla ha quedado enterrada en un surco fecundo». «De las épocas de violencia, como las que ahora atraviesa parte del mundo —escribió-, sólo subsistirán aquellas cosas que han sido perseguidas ${ }^{4} »$. 95-122.

1 ÁlVAREZ PELÁEZ, Raquel (1985), «Introducción al estudio de la eugenesia española», Quipu, 2,

2 Noguera, E. (1934), «Cómo se yuguló la generosa idea del Primer Curso Eugénico Español», en E. Noguera y L. Huerta, vol.2, pp

3 Sin propósito alguno de exhaustividad, citaremos a título de ejemplo algunas de ellas: ABAUNZA, A, (1928), «En torno a la eugénica», El Sol, 19 de abril; BASCUÑANA, L., (1928), «Eugenesia y eutanasia». Gaceta Gaditana de Ciencias Médicas , mayo-junio; BEJARANO, J., (1929), «El certificado médico prenupcial y las enfermedades venéreas», El Sol, 9 de abril; DARWIN, L., (1930), ¿Qué es la eugenesia? Madrid, Javier Morata; DELFINO, V., (1930), «El certificado de sanidad para cónyuges», Clínica y Laboratorio, 83; HARO, F., (1930), «El certificado sanitario prematrimonial o el reconocimiento médico prematrimonial», Heraldo de Madrid, 10 de marzo; HARO, F., (1929), «La eugenesia y la tocología en el Congreso de Beneficencia Católica de Barcelona», Heraldo de Madrid, 28 de noviembre; HARO, F., (1930), «El certificado médico prematrimonial», Clínica y Laboratorio, 96, diciembre; HUERTA, L., (1928), «Los fundamentos científicos de la eugénica», Gaceta Médica Española, 21-22; JIMÉNEZ DE ASÚA, L., (1928), «Aspecto jurídico de la maternidad consciente», Gaceta Médica Española, 6; KEHL, R., (1930), Pedagogía sexual. Lecciones de eugenesia. Madrid: Javier Morata; MARAÑóN, G., (1929), Amor, conveniencia y eugenesia. Madrid: Historia Nueva; NOGUERA, J., (1928), «La maternidad y el infanticidio ante el Derecho», Gaceta Médica Española, abril; NOGUERA, J., (1930), Moral, eugenesia y derecho. Madrid, Javier Morata; PANDO BAURA, J.L., (1928), «Medicina y Derecho. En torno a la eugenesia», La Medicina Ibera, 11 de agosto. PERERA, A., (1928), «Eugenesia y estética», La Medicina Ibera, 28 de abril; RECASENS, S., (1928), «Eugenesia y procreación», Gaceta Médica Española, 6; ROCAMORA, J., (1928), «Con motivo de una anécdota. Alrededor del eugenismo», El Liberal, 14 de marzo; SALAZAR, M., (1928), «La eugenesia desde el punto de vista sanitario», El Sol, 10 de mayo, 1928; TORRUBIANO RIPOLL, J., (1929), Al servicio del matrimonio. Teología y eugenesia. Madrid, Javier Morata; ZÁRRAGA, M., (1928), «ABC en Nueva York. Caprichos eugénicos», $A B C$, 4 de marzo.

4 MARAÑón, G. (1951), Ensayos sobre la vida sexual, en Obras completas, VIII, Madrid, Espasa Calpe, 1972, p 255. 


\section{EL PENSAMIENTO EUGÉNICO DE MARAÑÓN}

La caída de la Dictadura y el mayor aire de libertad que se anunciaba con el advenimiento de la República en 1931 prestaron nuevo impulso al movimiento eugénico. Nada tiene de extraño, pues, que uno de los libros sobre eugenesia publicados por aquellos años estuviese precisamente dedicado «a la República Española ${ }^{5}$ ». Porque la República significó para muchos «sobre todo, vida nueva, universal, abierta a los progresos justos. Y que es esto lo que, en efecto significa, lo demuestra bien el hecho de que hoy podamos hablar así de eugenesia. Mientras que hace unos años la propia Universidad se cerraba a estas verdades tan nobles porque así lo quería el poder arbitrario e imperialista, al servicio de una moral farisaica ${ }^{6}$ ».

Este nuevo auge de la eugenesia en España culminó con las realización de unas Primeras Jornadas Eugénicas celebradas en Madrid del 21 de abril al 10 de mayo de 1933, que esta vez se llevaron a cabo con el beneplácito de las autoridades: de hecho, la conferencia inaugural («La eugenesia en la Universidad») fue pronunciada por el entonces Ministro de Instrucción Pública, Fernando de los Ríos, y para la clausura estaba prevista nada menos que la asistencia del mismo Manuel Azaña, Presidente de la República? .

\section{MARAÑÓN ANTE LA EUGENESIA}

Son éstos, pues, unos años cruciales para la historia reciente de la eugenesia en España, y en ellos el doctor Marañón iba a desempeñar un papel singular. Será, por lo pronto, espectador de todos estos acontecimientos, y como tal los reflejará en diversos pasajes de su obra ${ }^{8}$. Pero también iba a ser un eminente protagonista de los mismos, ya que él fue uno de los conferenciantes que no pudieron llegar a tomar la palabra en aquel abortado Primer Curso de Eugenesia y, por ello, fue también invitado a participar con carácter preferente en las Jornadas Eugénicas celebradas cinco años más tarde?.

El hecho no tiene nada de sorprendente, ya que Marañón venía ocupándose de cuestiones eugénicas al menos desde 1920, en que las abordaba directamente en su ensayo «Biología y feminismo». Al movimiento eugénico, «siquiera sea en la parca medida de centinela de vanguardia ${ }^{10}$, asociaba también Marañón sus Tres ensayos

\footnotetext{
5 HARO, F. (1932), Eugenesia y matrimonio, Madrid, Javier Morata.

6 MARAÑón, G., (1931), «Eugenesia y moral», en Obras completas, I, Madrid, Espasa Calpe, 1966, p. 101

7 Noguera, E., (1934), «Cómo se yuguló la generosa idea del Primer Curso Eugénico Español», en Noguera, E. y Huerta, L., (eds), Genética, Eugenesia y Pedagogía Sexual. Libro de las Primeras Jornadas Eugénicas Españolas, 2 vols., Madrid, Javier Morata.

8 Cfr., MARAÑón, G., (1951), nota 4.

9 Noguera, E. y HuERTA, L. (1934), nota 7.

10 MARAÑón, G., (1951), nota 4, p. 255
} 


\section{ALEJANDRA FERRÁNDIZ Y ENRIQUE LAFUENTE}

sobre la vida sexual de 1926. Pero la mayor importancia de Marañón en relación con la eugenesia probablemente quepa cifrarla en su tremenda eficacia como divulgador.

En los años 20, Marañón se había convertido en una de las figuras públicas de mayor relieve de todo el país. Era, sin lugar a dudas, el médico de moda. Pero era también mucho más que eso. Trabajador infatigable, su labor científica era reconocida y admirada dentro y fuera de nuestras fronteras. Escritor, además, sumamente prolífico, no se ocupaba sólo de abstrusos temas científicos y médicos, sino que lo hacía también, cada vez con mayor frecuencia, de los asuntos más generales de la vida y la política españolas del momento. Su estilo sencillo y directo, potenciado por la enorme sugestión que ejercían su atrayente personalidad y su enorme prestigio, dotaba a sus escritos de un poder de comunicación y persuasión incalculable. El impacto, pues, de su defensa del ideal eugénico sobre la sociedad española no puede ser ignorado ${ }^{11}$.

Marañón no escribió nunca un tratado de eugenesia. En ningún momento pretendió exponer sus ideas de forma sistemática en un libro. El único que dedicó expresamente al tema, Amor y eugenesia ${ }^{12}$ no es en realidad sino una colección de artículos independientes, bien que enlazados por una preocupación común. Pero los escritos dispersos que Marañón nos ha legado sobre este asunto contienen ideas que, a nuestro juicio, componen una auténtica doctrina eugénica. En este trabajo procuramos reconstruir la figura sistemática de tales ideas, subrayando las principales líneas de problemas que para Marañón plantea la cuestión. Aspiramos de este modo a recuperar una pieza que nos parece clave para comprender cabalmente el desarrollo de las ideas eugénicas en nuestro país.

\section{EL PUNTO DE PARTIDA: EUGENESIA Y MORTALIDAD INFANTIL}

El primer acercamiento explícito de Marañón al tema eugénico se produce en 1920, en una conferencia pronunciada ante la Sociedad Económica de Amigos del País, de Sevilla, y publicada después en El Siglo Médico con el título «Biología y feminismo ${ }^{13}$ ». Más tarde, en 1926, buena parte de su contenido pasaría a ser incorpo-

11 Sobre la vida y la obra de Marañón, cfr. SÁNCHEZ GRANJEL, L., (1960), Gregorio Marañón: su vida y su obra, Madrid, Guadarrama; LAín, P., (1969), Gregorio Marañón: Vida, obra y persona, Madrid, Espasa Calpe; GómeZ SANTOS, M., (1971), Vida de Gregorio Marañón, Madrid, Taurus; FERRÁNDIZ, A., (1988), Aproximación psicológica a Marañón: su biografía y su bibliografía, Madrid, Ministerio de Cultura.

12 MARAÑón, G., (1931), Amor y eugenesia, en Obras completas, VIII, Madrid, Espasa Calpe.

13 Marañón, G., (1920), «Biología y feminismo», en Obras completas, III, Madrid, Espasa Calpe, $1972\left(2^{\mathrm{a}}\right.$ ed.). 
rado a uno de sus Tres ensayos sobre la vida sexual, sin duda uno de los libros marañonianos que gozaron de mayor popularidad.

En estos escritos Marañón se refería a unas estadísticas realizadas por él mismo en el Hospital General de Madrid que revelaban, según sus propias palabras, «una ley aterradora»: la de que «la fecundidad de las madres está en relación directa con la mortalidad de los hijos ${ }^{14}$ ». En efecto, en la primera de estas estadísticas se ponía de manifiesto que, de los 7.387 hijos de una muestra de 1.534 familias de clase proletaria y media muy baja, casi la mitad (3.451) habían muerto muy jóvenes. En la segunda de ellas, Marañón ponía en relación el número de hijos de cada una de estas familias con el número de familias que conservaban la totalidad de los mismos, y descubría que esta última cifra descendía aceleradamente a partir del quinto, hasta llegar a un punto, de 13 hijos en adelante, en que ninguna de las familias de la muestra había logrado conservarlos a todos.

A pesar de que estas cifras no eran muy distintas de las obtenidas en otros países europeos, su publicación en el nuestro cobra una significación especial. Ante todo, porque era la primera vez que en España se publicaban estadísticas de este tipo. En segundo lugar, porque en ninguno de los otros países se evidenciaba como en el nuestro la magnitud del problema. Finalmente, por el extraordinario revuelo que suscitó la lectura eugénica que Marañón hizo de ellas ${ }^{15}$.

Para el médico español la cosa estaba bastante clara: la razón de que casi todos estos hijos de familias numerosas desaparezcan antes de llegar a ser hombres y mujeres útiles es que las madres no han podido engendrarlos suficientemente fuertes, ni ocuparse luego debidamente de su debilidad o enfermedades, ya que carecen de recursos y el Estado no se cuida de proporcionárselos. Hay, pues, por lo pronto, razones biológicas, económicas y políticas que explican este estado de cosas. Hay también, además, razones de índole educativa: Marañón se lamenta de la falta de instrucción de las madres, que tienen hijos «sin atenerse a normas de fisiología, de humanidad y de moral» ${ }^{16}$. En general, a su juicio, es la ignorancia de hombres y mujeres en las cuestiones relacionadas con el sexo lo que determina que la maternidad termine convirtiéndose en una fuente de sufrimientos y tristeza. A la vista de estos datos y del negro «porvenir de nuestra raza» que permitían augurar, Marañón abogó por la regulación de la natalidad como único medio eficaz de hacer frente a la situación. Y vino a formular así una tesis aparentemente paradójica: «si las mujeres españolas parieran la mitad de hijos que en la actualidad, en cien años se duplicaba la población de España ${ }^{17}$. Esta tesis, claro está, tropezaba con la doctrina oficial de la Iglesia, o al

\footnotetext{
14 MARAÑóN, G. (1920), nota 13, p. 19; (1951), nota 4, p. 297.

15 MARAÑón, G., (1933), «Relación de la eugenesia con la mortalidad infantil», en Obras completas, III, Madrid, Espasa Calpe, 1966.

16 MARAÑóN, G., (1951), nota 4, p. 299.

17 MARAÑóN, G., (1951), nota 4, p. 298.
} 


\section{ALEJANDRA FERRÁNDIZ Y ENRIQUE LAFUENTE}

menos de la Iglesia española, que seguía defendiendo a ultranza la naturaleza pecaminosa de la limitación voluntaria de la natalidad dentro del matrimonio ${ }^{18}$. Era preciso, pues, si se quería que las ideas eugénicas arraigasen de verdad en nuestro país, ocuparse también de esta dimensión moral del problema, y a ella destinaría Marañón buena parte de sus reflexiones eugénicas.

Como puede apreciarse, pues, en este primer escrito suyo sobre el tema Marañón presentaba todo el abanico de dimensiones con que la cuestión eugenica se ofrecía a su mirada. Examinaremos a continuación con algún detalle estas diversas facetas que el médico español iba a ir desentrañando en sus escritos posteriores.

\section{EUGENESIA Y BIOLOGÍA}

El primer aspecto implicado en la paternidad es, claro está, el de la aptitud concepcional ${ }^{19}$. Claro que no es el único (como veremos, Marañón insistirá siempre en la exigencia que la vida moderna impone de poseer también una cierta capacidad económica), pero es el requisito previo, una condición indispensable para que el problema mismo pueda llegar siquiera a plantearse.

Las capacidades biológicas con que deben contar los padres, sin embargo, no son sólo las estrictamente concepcionales. «Nadie debe aventurarse en el maravilloso albur de tener hijos —escribió en cierta ocasión- sin reunir el mínimo de posibilidades biológicas ... de que los hijos se puedan criar dignamente ${ }^{20}$ ». En otras palabras, lo que Marañón subraya es la salud como exigencia para acceder al matrimonio: «Quien no está suficientemente sano no se debe casar ${ }^{21}$ ».

Esta exigencia de salud de los padres y los hijos determina, a su vez, desde su punto de vista, un segundo requisito: el de la continencia juvenil. Según Marañón, en la juventud el impulso sexual es vacilante y débil, y la aptitud para el amor físico es todavía muy limitada. El óptimo desarrollo del individuo y de la raza requieren un ejercicio sexual tardío, porque en su opinión la sexualidad precoz tiene consecuencias debilitantes, incrementa el peligro de contagio venéreo e inhibe el desarrollo físico. «Una de las razones de la talla baja y de la mezquindad física de muchos pueblos meridionales se debe al comienzo temprano de la vida sexual», había escrito. La continencia juvenil, por tanto, es un «precepto eugenésico de primordial importancia ${ }^{22}$ ».

Por otra parte, la salud como exigencia plantea de inmediato el problema de la enfermedad, sobre todo de las enfermedades que se pueden transmitir. A este respecto,

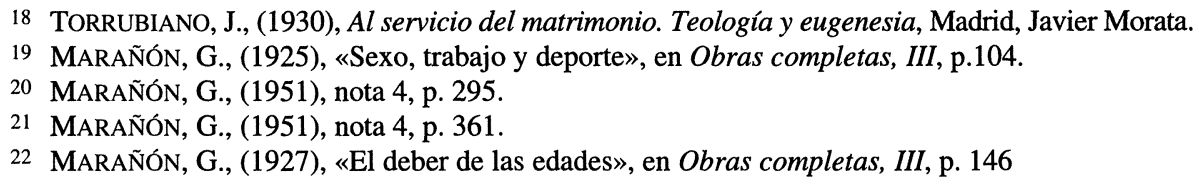




\section{EL PENSAMIENTO EUGÉNICO DE MARAÑÓN}

Marañón se opone frontalmente a lo que él denomina el «argumento sentimental», que vendría a formularse así: ¿Cómo se puede separar a dos jóvenes que se quieren, y hacerlo además en razón de su enfermedad? La respuesta de Marañón es tajante: los hijos no tienen la culpa de que ejerzamos nuestro sentimentalismo a su costa. En este punto el médico español sitúa claramente la conveniencia de la especie por encima del amor, y defiende así el matrimonio de conveniencia, no como algo contrapuesto, sino como complementario del matrimonio por amor. En el matrimonio, en efecto, no debe faltar nunca el amor entendido como atracción instintiva de los sexos. Pero el instinto solo es casi siempre «fundamentalmente antieugenésico ${ }^{23}$ », no repara en la salud o enfermedad de su objeto; por ello debe ser completado por la conveniencia en su sentido más noble, la conveniencia de la especie. Hay que terminar, pues, con el «equívoco romántico y dañino» del matrimonio como «aventura de amor»: «Los poetas nos maldecirán. Pero la bendición de nuestros hijos nos consolará de sus maldiciones. Y, a la postre, los poetas nos darán también la razón y dedicarán sus sonetos a la prole robusta y alegre, como hoy se los dedican a la luna ${ }^{24}$ ».

En suma, Marañón excluye de la paternidad a los seres enfermos, por más que éstos no tengan culpa alguna de su enfermedad y sea doloroso añadir a su sufrimiento físico el sufrimiento moral de la infecundidad. Pero los padres enfermos de enfermedades transmisibles no pueden tener hijos: es preferible que sufran ellos un momento a que sus hijos sufran luego toda la vida. La posición de Marañón es, pues, terminante: quien no se pueda curar no debe ser padre nunca ${ }^{25}$.

\section{EUGENESIA Y ECONOMÍA}

Pero, como hemos visto, no son sólo las posibilidades biológicas, sino también las materiales, las que deben exigirse, desde el punto de vista eugénico, para tener hijos. ¿Dónde situar, sin embargo, ese «mínimo de posibilidades» exigible? Cuando Marañón analiza ésta como una de las razones que con mayor frecuencia aducen los matrimonios jóvenes para no tener descendencia, llega a la conclusión de que suele ser una excusa insuficiente, y que la paternidad verdaderamente deseada es compatible con medios económicos sumamente precarios ${ }^{26}$. Por otra parte, la necesidad de que éstos sean suficientes para criar dignamente a los hijos hace que ésta sea una cuestión perfectamente legítima de plantear por la mujer a la hora de elegir marido. Por la mujer, adviértase bien, no por el hombre. Porque el hombre, según Marañón, lo que

\footnotetext{
23 MARAÑón, G., (1951), nota 4, p. 322,

24 MARAÑón, G., (1951), nota 4, p. 364.

25 MARAÑón, G., (1933), Raíz y decoro de España, Madrid, Espasa Calpe. 1973.

26 MARAÑón, G., (1939), «El pánico del instinto», en Obras completas, IX, Madrid, Espasa Calpe,
} 


\section{ALEJANDRA FERRÁNDIZ Y ENRIQUE LAFUENTE}

deberá buscar en la mujer no es sólo a la compañera, sino sobre todo a la madre óptima, la que mejor pueda concebir y criar a los hijos; la mujer, por el contrario, habrá de buscar al más capacitado para vencer en la lucha por la vida. La mujer, pues, obra con «cordura natural» cuando prefiere al robusto, al poderoso, al rico; el hombre que valora a la mujer por su dote, en cambio, «procede contra el orden natural de los instintos y es un remedo de varón ${ }^{27}$ ».

Pero, ¿y cuando la elección de los esposos ya está hecha y nos enfrentamos a una pareja de pobres de solemnidad? ¿Habrá que impedir que se reproduzcan por razones eugénicas? Evidentemente no, y Marañón lo reconoce así y remite el problema a una instancia superior a los propios individuos, a la labor protectora del Estado.

Así como en el caso del enfermo Marañón es inflexible —el enfermo no debe reproducirse-, en el caso del pobre, en cambio, admite una salida, aunque reconoce que se trata del «aspecto más delicado de la Eugenesia ${ }^{28}$ ». Según él, el Estado debe velar porque el hijo no sea una carga económica para los padres, para que éstos cuenten con lo necesario para la crianza normal y la elemental educación de aquél. No se trata de premiar a las familias numerosísimas, sino de ayudar a las que empiezan: las que no se atreven a tener sucesión por falta de recursos, o las que no pueden hacer vivir dignamente a sus hijos, que crecen en el raquitismo y la incultura. Y no para que tengan muchos hijos, sino tan sólo para que los puedan atender debidamente. No es otro, para Marañón, el fin preciso al que debe tender la eugenesia: «marcar ese punto, en el que el mayor número posible de hijos deja de ser inofensivo para la propia descendencia ${ }^{29} 》$.

\section{EUGENESIA Y POLÍTICA}

Esto nos lleva a la dimensión política de la eugenesia, presente siempre en el pensamiento de Marañón, aunque más como telón de fondo permanente que como objeto de un planteamiento explícito y directo. La eugenesia plantea, en efecto, problemas políticos de varios órdenes. Uno de ellos nos ha aparecido ya en la necesidad de que el Estado intervenga facilitando ayuda económica a los matrimonios pobres, de modo que la pobreza no sea nunca un obstáculo para tener hijos ni para cuidarlos adecuadamente. No es, pues, sólo ayuda económica, sino también ayuda médica y educativa lo que el programa eugénico reclama por parte del Estado.

Pero la intervención del Estado es también exigible para vigilar que los enfermos de enfermedades transmisibles no tengan descendencia. Marañón se hace eco de la campaña que tanto en nuestro país como fuera de él venía haciéndose en favor del

27 MARAÑón, G., (1927), «Amor, conveniencia y eugenesia», en Obras completas, III, p. 126.

28 MARAÑón, G., (1933), nota 25, p. 103.

29 MARAÑón, G., (1933), nota 25, p. 108 


\section{EL PENSAMIENTO EUGÉNICO DE MARAÑÓN}

certificado médico como requisito esencial previo para el matrimonio. En este sentido, recoge la sugerencia de Richet de eliminar de la paternidad a cuantos se exime del servicio militar por enfermos, defectuosos o débiles, y se escandaliza de que las lacras que un joven casi desea tener para quedar exento de semejante servicio no sean sin embargo obstáculo alguno para unirse a una mujer sana, infectarla y hacerla concebir hijos degenerados y enfermos. «Se seleccionan los fuertes para morir - se lamentaen plena juventud, en el campo de batalla defendiendo la patria, lo cual está bien; pero no el que a los residuos de esta selección se les encargue de perpetuar la especie ${ }^{30}{ }_{\gg}$.

A pesar de ello, Marañón es profundamente pesimista respecto de la eficacia que el certificado médico prenupcial u otras medidas semejantes pudieran tener en España:

\footnotetext{
«En la práctica, el escamoteo de la verdad sería constante. Nada resolvería el certificado, porque los médicos, generalmente, emplean estos documentos para darse el gusto de decir en un papel oficial cosas contrarias a la verdad. Aun en los certificados de defunción, en los que la realidad es aplastante, varían la hora del fallecimiento, el nombre de la enfermedad y todo lo que pueden. ¡Qué no harían - qué no haríamos-en estos casos en que el amor padecería con nuestra decisión, cuando la tradición nuestra es precisamente la de adoptar la actitud comprensiva y blanda, tan típica de los doctores de las comedias, de los que todos tenemos un poco! ${ }^{31}$ ».
}

Desconfía, pues, Marañón de la viabilidad de tales medidas estatales y apuesta más bien por la mucho más lenta, pero también más segura eficacia de la educación: «El camino es distinto. No prohibir, a la fuerza, la insensatez en marcha tratando de sofocar con un informe técnico el amor ya encendido; sino evitar la insensatez, inculcando, a tiempo, en la cabeza de los jóvenes que si no tienen salud no deben tener hijos, no tienen el derecho de tenerlos ${ }^{32}$ ».

El Estado debe ejercer, así, una labor tutelar en orden a la mejora de la raza por la vía de la ayuda económica, del control de la transmisión hereditaria de defectos y enfermedades y, sobre todo, de la adecuada educación de la juventud.

La eugenesia representa, además, para Marañón, una solución de amplio y profundo alcance político, ya que, según su diagnóstico, la raíz de los males de la humanidad en el momento en que escribe (1931) es precisamente el exceso de población. «La enorme conmoción que hoy pone a la Humanidad en uno de los trances más graves de su historia es, en el fondo, una crisis de exceso de población ... Se juega una inmensa partida de ajedrez con piezas que se llaman capital, socialismo, comunismo, sindicalismo, orden, revuelta, represión, huelga, paro forzoso, impuestos ... Pero debajo de todo ello está la realidad neta y trágica de que sobran hombres, para

30 MARAÑón, G., (1951), nota 4, p. 363.
31 MARAÑóN, G., (1951), nota 4, p. 362.
32 Marañón, G., (1951), nota 4, p. 362. 


\section{ALEJANDRA FERRÁNDIZ Y ENRIQUE LAFUENTE}

la situación actual del planeta ${ }^{33}$ ». Marañón apunta soluciones a largo plazo, como las de dispersar la población por tierras aún vacías, romper el magnetismo de las ciudades y variar la estructura económica imperante para ampliar los límites del mundo aprovechable. Entre tanto, sin embargo, reclama que se oiga la voz de la ciencia para procurar limpiar las nuevas generaciones de hombres degenerados, enfermos e inútiles, en la medida en que esta selección esté al alcance de la voluntad.

Situado en esta perspectiva de los problemas esenciales de la Humanidad, no es de extrañar que Marañón, haciendo suyo el sentir de Keyserling, considere que «la hora actual del mundo... es la hora de la eugenesia» y califique a ésta de «magnífico ideal de nuestros tiempos ${ }^{34} »$. La eugenesia, escribe en otro lugar, es «la noble ciencia, sin la cual no tendrían solución los problemas del mundo actual - guerras, revoluciones, hambre, crisis-; problemas que están en gran parte producidos por la población excesiva y por el predominio de hombres enfermos y anormales sobre los sanos y rectos de intención y de conducta ${ }^{35}{ }_{»}$.

\section{EUGENESIA Y EDUCACIÓN}

Entre las exigencias que la eugenesia plantea, la de lograr una educación eficaz sobre sus cuestiones es quizá para Marañón, como veíamos antes, una de las más básicas.

Sería preciso, ante todo, educar a las madres, cuya ignorancia en las cuestiones relativas a su propia maternidad denuncia Marañón repetidamente. En última instancia, tal viene a ser la consecuencia fundamental que puede derivarse de las cifras sobre la mortalidad infantil que constituyen el punto de partida de sus reflexiones sobre este asunto. «Muchas mujeres - escribió- van a la maternidad y la practican luego, henchidas del más puro y entrañable instinto materno, pero en un grado de desconocimiento peligroso de la trascendencia de su misión ${ }^{36} »$. $\mathrm{Y}$, en otro lugar: «Hay ... que decir a gritos a las madres españolas que 'no saben ser madres', por mucha generosidad que pongan en su empeño ... no hay pecado comparable a la ignorancia de su supremo deber: que no es traer hijos a este mundo, sino conservarlos ${ }^{37} »$. No debe sorprender, pues, el hecho de que su libro Amor y eugenesia aparezca dedicado al gran pedagogo M.B. Cossío, cabeza visible, desde la muerte de Giner de los Ríos en 1915, de ese espléndido movimiento de renovación pedagógica española que representó la Institución Libre de Enseñanza.

\footnotetext{
33 MARAÑón, G., (1931), «Eugenesia y moral», en Obras completas, I, Madrid, Espasa Calpe, p. 100.

34 MARAÑón, G., (1927), «Amor, conveniencia y eugenesia», en Obras completas, III, p. 114.

35 MARAÑón, G., (1933), Raíz y decoro de España, Madrid, Espasa Calpe, p. 108.

36 MARAÑón, G., (1951), nota 4, p. 295.

37 MARAÑón, G., (1927), «Amor, conveniencia y eugenesia», Obras completas, III, p. 119.
} 


\section{EL PENSAMIENTO EUGÉNICO DE MARAÑÓN}

Pero, indudablemente, si se quiere atajar el mal en su raíz, la educación eugénica debe comenzar antes, esto es, debe proyectarse sobre los padres y las madres cuando todavía no lo son. Así, Marañón reclamaba una «enseñanza oficial» de las cuestiones eugénicas relacionadas con la mortalidad infantil, que estuviese en manos de la autoridad sanitaria de los hombres de ciencia ${ }^{38}$. Una enseñanza que, entre otras cosas, inculcase a tiempo en la cabeza de los jóvenes que si no tienen salud no deben tener hijos ${ }^{39}$.

Esta preocupación marañoniana por lograr una educación eugénica eficaz que alcanzase a todos los sectores de la población («hay... que limpiar definitivamente esta palabra - Eugenesia- de ese dejo diabólico con que resuena todavía en muchos estratos de la sociedad $\left.{ }^{40} \gg\right)$, enlaza con otra preocupación suya de carácter más general pero muy estrechamente relacionada con ella: la cuestión de la educación sexual; una preocupación, por lo demás, que comparte con otros ilustres coetáneos suyos, como sus amigos el Dr. Rodríguez Lafora y el novelista Pérez de Ayala, que pocos años antes había publicado dos novelas sobre las desastrosas consecuencias que se siguen de llegar al matrimonio en la más absoluta ignorancia sexual ${ }^{41}$.

Marañón no dudaba en considerar esta ignorancia sexual de la juventud española como uno de los factores que más decisivamente influían en las altas cifras de mortalidad infantil que arrojaban sus estadísticas ${ }^{42}$. Y reprochaba en este sentido a los padres el olvido frecuente del «deber primordial aun cuando sea ingrato, de iluminar en lo posible el camino tortuoso que sus hijos tienen que andar antes de ser hombres y mujeres en toda su integridad ${ }^{43}$ ».

La trascendencia que atribuía Marañón al tema se echa de ver en declaraciones como la siguiente:

«Cuando los europeos tenemos que inclinar la cabeza ante la pujanza actual de América del Norte, si buscamos una razón que nos explique su ascensión creciente, a mí me parece que no encontramos otra clave más significativa que la educación sexual de la juventud, ... la educación sexual, razonada y clara, que conserva a la parte más considerable de los jóvenes en un estado de despreocupación sexual hasta bien entrada la vida; eso sí que nos da la razón de los triunfos de la raza entera ${ }^{44}{ }{ }_{\text {.. }}$

\footnotetext{
38 MARAÑóN, G., (1933) «Relación de la eugenesia con la mortalidad infantil», en Obras completas, III, 1972.

39 MARÃ̃ón, G., (1951), nota 35, p. 361.

40 MARAÑóN, G., (1933), nota 38, p. 100.

41 PÉReZ De Ayala, R., (1923/1969), Las novelas de Urbano y Simona, Madrid, Alianza; RoDRÍGUEZ LAFORA, G., (1933), La educación sexual y la reforma de la moral sexual, Revista de pedagogía, Madrid.

42 MARAÑón, G., (1920), (1951).

43 MARAÑón, G., (1927), «El deber de las edades», en Obras completas, III, p. 145.

44 Ibidem, p. 146.
} 


\section{ALEJANDRA FERRÁNDIZ Y ENRIQUE LAFUENTE}

Una adecuada educación sexual contribuiría, pues, a mantener al joven en una «virilidad inédita y pletórica, no una virilidad gastada a destiempo ${ }^{45}$ », y es precisa, por tanto, para el perfeccionamiento de la raza. La educación sexual, por consiguiente, viene a ser así un requisito eugénico fundamental.

\section{EUGENESIA Y MORAL}

Ni un paso adelante podrá darse, sin embargo, en este programa eugenésico Marañón lo ve bien - si previamente no se salvan los obstáculos que a su realización opone la rígida moral tradicional de los españoles en cuestiones de sexo. A este respecto, Marañón pensaba que los dogmas morales clásicos habían perdido buena parte de su eficacia ${ }^{46}$, y que era preciso proceder a su renovación. Que esto era así se ponía de manifiesto de forma inequívoca, según Marañón, en el ejemplo de multitud de familias españolas que, bajo la capa de una intachable moral externa, no conseguían sin embargo atender debidamente a los hijos, muchos de los cuales morían mientras los demás se educaban deficientemente porque los padres no tenían tiempo ni dinero para ocuparse de ellos ${ }^{47}$. Para él éstas eran familias reprobables desde un punto de vista moral superior al tradicional.

A esta moral tradicional de los españoles opone Marañón dos objeciones fundamentales. Una es que, al defender la procreación ilimitada, defiende también, implícitamente, el adulterio y la prostitución. Marañón plantea el dilema en los siguientes términos: «si se acepta la prohibición rigurosa de la limitación voluntaria de la maternidad, se abre automáticamente la puerta del adulterio ${ }^{48} \gg$. En efecto, si atendiendo al imperativo de la moral al uso, los esposos llenan el hogar de hijos a los que no alcanza ni el alimento, ni el buen humor, ni la capacidad educadora de los padres, la madre envejecerá prematuramente, estará constantemente malhumorada o enferma, llegará a temer el lecho conyugal, perderá la alegría de la maternidad y, con todo ello, el encanto sexual para el marido, que no tardará en encontrar una sustituta extramatrimonial ${ }^{49}$.

Una segunda objeción se refiere a la contradicción que supone rechazar la prohibición de reproducirse a los enfermos y aceptar, en cambio, la inmoralidad de hacer hijos desgraciados por gozar de unos minutos de placer ${ }^{50}$. Para Marañón es inmoral

\footnotetext{
45 Ibidem, p. 146.

46 MARAÑón, G., (1951), nota 4.

47 MARAÑón, G., (1927), «Amor, conveniencia y eugenesia», Obras completas, III, Madrid, Espasa Calpe, 1972.

48 MARAÑón, G., (1951), nota 4, p. 299.

49 MARAÑón, G., (1951), nota 4.

50 MARAÑón, G., (1931), nota 12, p. 442
} 


\section{EL PENSAMIENTO EUGÉNICO DE MARAÑÓN}

poner la moral como pretexto para sacrificar a un minuto de placer el dolor de toda una vida. Desde el punto de vista moral, nada puede justificar el hecho de traer hijos a este mundo con la conciencia de que no van a poder ser debidamente atendidos ${ }^{51}$.

Así, a esta moral del «puritanismo hipersensible ${ }^{52}$ », Marañón contrapone una especie de moral natural $\multimap$ acaso fuera más apropiado calificarla de naturalista, biologista o incluso cientista-: hay que renovar los dogmas morales «a la luz de la ciencia», escribe por ejemplo ${ }^{53}$; o: «lo importante es no transigir ante la solución biológica», que es «única y sagrada ${ }^{54}$; o, en sentido análogo: «lo que no puede admitirse es, so pretexto de no pecar, traer al mundo una serie de entes ineducados y enfermos, que son ya pecados vivos contra la Naturaleza y, por lo tanto, contra quien la rige ... Porque nunca pensamos lo suficiente en que la bondad es el fruto normal de la salud ${ }^{55}$ ». «Los hombres no empezarán a ser buenos —escribe en otro lugar- hasta que dejen de sufrir hambre y empiecen a estar radical y colectivamente sanos ${ }^{56}{ }_{\text {». }}$.

El criterio supremo de esta moral naturalista marañoniana será el criterio eugénico, el criterio de la conveniencia de la especie. Para Marañón el matrimonio no se ordena a la satisfacción de los cónyuges, sino a la creación de hijos; solo que no se trata simplemente de hacerlos nacer, sino de hacerlos vivir y perfeccionarse. El matrimonio debe ser, en suma, el esfuerzo de los hombres para perpetuar la especie y mejorarla. «La noble conveniencia de la especie está por encima de todo», escribirá en este sentido ${ }^{57}$; y también: «toda moral que se opone a las conveniencias de la raza, perece ${ }^{58}$.

Marañón no fue, sin embargo, ningún revolucionario moral. Su talante en éste, como en muchos otros terrenos, fue siempre moderado, conciliador, acorde con su actitud liberal en todos los planos de la vida. Por ello defendió la alianza de la eugenesia con la «moral más púdica ${ }^{59}$ », y propugnó la colaboración del investigador positivista con el moralista en el estudio de las cuestiones eugénicas. Marañón aspiraba a que todos se oyesen con respeto -recuérdese aquella máxima suprema de su credo liberal: «estar dispuesto a entenderse con el que piensa de otro modo ${ }^{60}$ », a que se buscase el plano de intersección entre la conveniencia moral y la conveniencia orgánica; a que se llegase, en suma, a un «acuerdo iluminado por la caridad y la tolerancia de todos del que resulte que el alma y el cuerpo que Dios creó en tan íntimo con-

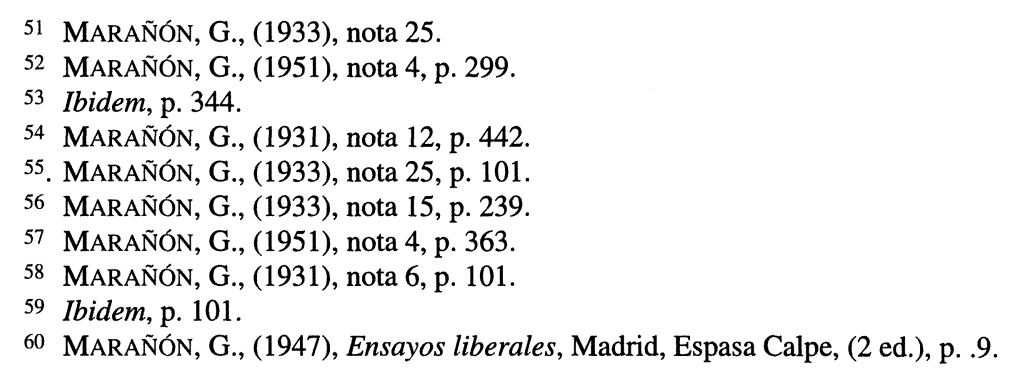




\section{ALEJANDRA FERRÁNDIZ Y ENRIQUE LAFUENTE}

tacto y en tan fácil convivencia no vengan a ser dos cosas incompatibles a fuerza de discursos de los naturalistas y de susceptibilidades de los teólogos ${ }^{61}{ }^{\text {». }}$.

Acaso el terreno más delicado, donde abiertamente podía producirse el conflicto entre la nueva moral eugénica y la moral tradicional, fuera el de las propuestas concretas de procedimientos para alcanzar el fin eugénico, las propuestas de técnicas para regular voluntariamente la natalidad. Marañón procuró mantener sus sugerencias dentro de la más rigurosa ortodoxia católica : «La limitación voluntaria, sistemática y arbitraria de la maternidad constituye un atentado contra la sociedad y, para nosotros los católicos, un pecado ${ }^{62}$ ». Para Marañón, pues, católico practicante, el fin esencial del matrimonio es la procreación, y considera un crimen que una pareja humana la evite por no sacrificar lujo o tiempo.

Por otro lado, sin embargo, la atenencia al principio de no hacer daño a sabiendas no puede contradecir moral ni religión alguna ${ }^{63}$, y este principio puede obligar, en ocasiones, a evitar la procreación para no engendrar hijos con la conciencia de que su vida material o afectiva será precaria. $\mathrm{Al}$ cabo, pues, prevalece el criterio eugénico, que Marañón considera, empero, compatible con sus convicciones religiosas: «Claro que la limitación consciente de la maternidad alcanzará su máxima perfección moral, si se basa en la separación honesta de los cónyuges, sin detrimento del amor y sin relajamiento de los deberes conyugales. Nosotros no osaríamos aconsejar otra técnica que no fuera ésta ${ }^{64} \gg$.

También las convicciones religiosas, sin embargo, terminan cediendo paso a unas convicciones que parecen tener en Marañón un alcance todavía más amplio que aquéllas, su fe en lo humano universal, que trasciende cualquier forma particular de código religioso ${ }^{65}$. Así, el consejo médico arriba expresado estaría condicionado siempre a que «se cumpla rigurosamente y de una manera bilateral. Porque si el marido tranquiliza su conciencia con la separación material de la mujer legítima, pero tranquiliza a la vez sus instintos en el adulterio, como ocurre casi siempre, el médico debe tener el valor de aconsejar lo menos malo para la Humanidad, para el hogar, para el propio individuo, y seguramente para Dios, esto es, el amor entre los cónyuges, aunque sea, para la especie, intrascendente ${ }^{66_{»}}$.

A última hora, por tanto, Marañón, más liberal que católico estricto, termina erigiendo a la conciencia de cada uno en único consejero moral válido. Pero sólo en lo

61 MARAÑón G., (1929), «Breve prólogo sobre los prólogos y sobre la pasión provechosa», en Obras completas, I, Madrid, Espasa Calpe, 1966, p. 476.

62 MARAÑón, G., (1951), nota 4, p. 299.

63 MARAÑón, G., (1933), nota 25.

64 MARAÑón, G., (1951), nota 4, p. 301.

65 MARAÑón, G., (1933), nota 25.

66 MARAÑón, G., (1951), nota 4, p. 301. 


\title{
EL PENSAMIENTO EUGÉNICO DE MARAÑÓN
}

que respecta a los medios, porque, en lo que se refiere a los fines, sigue siendo la conveniencia de la especie el criterio inapelable:

\begin{abstract}
«Que cada cual busque las soluciones que se avengan mejor con su conciencia. Lo importante es no transigir ante la solución biológica, única y sagrada, difundiendo entre los jóvenes desde el comienzo de su educación la idea fundamental de que sin salud no se puede ser padre. El enfermo debe saber esto antes de enamorarse, y recluirse en la castidad o aceptar la relación conyugal con el compromiso de que sea infecunda ${ }^{67}$ ».
\end{abstract}

\section{CONCLUSIÓN}

El pensamiento de Marañón sobre eugenesia constituye un difícil intento de matener el equilibrio entre tradición y progreso. Si sus ideas presentan indudables vacilaciones y aun contradicciones es precisamente por eso, por querer estar a la altura de unos tiempos nuevos sin querer romper del todo, empero, con unas firmes convicciones heredadas del pasado.

Sus propuestas resultan hoy, sin duda, discutibles e insuficientes como respuesta a los innumerables problemas, teóricos y prácticos, que las cuestiones eugénicas suscitan en la actualidad. Pero en el clima de extremada polarización ideológica en que fueron presentadas ${ }^{68}$, entre unos sectores conservadores para quienes la discusión pública de las cuestiones eugénicas era motivo de escándalo, y los sectores más radicalizados de la sociedad, que parecían a veces querer convertir la eugenesia en un instrumento más de agresión política, las posiciones de Marañón representaban una tercera vía de moderación y concordia que acaso constituyese la mejor condición de posibilidad para el desarrollo de la eugenesia española.

La contribución de Marañón, en este sentido, resulta enormemente significativa. Nuestro trabajo no ha pretendido otra cosa que presentarla en sus internas conexiones e inconsistencias.

\section{REFERENCIAS BIBLIOGRÁFICAS}

ÁlVARez PeláeZ, R. (1988), «Origen y desarrollo de la eugenesia en España», en Ciencia y sociedad en España, José Manuel Sánchez Ron, ed., Madrid, el Arquero/CSIC, pp 179-204.

Álvarez Peláez, R., (1988), «Eugenesia y control social», Asclepio, 40 (2), pp 29-80.

ÁlVAREZ PeLÁEZ, R. (1990), «La mujer española y el control de natalidad en los comienzos del siglo XX», Asclepio, 42, (2), pp 175-200.

67 MARAÑóN, G., (1931), nota 12, p. 442

68 ÁLVAREZ PELÁEZ, R., (1985), «Introducción al estudio de la eugenesia española (1900-1936)», Quipu, 2, 95-122. 


\section{ALEJANDRA FERRÁNDIZ Y ENRIQUE LAFUENTE}

Álvarez PelÁEZ, R., (1990), «Medicina y moral sexual en la España de preguerra», Asclepio, 42, (2), pp 201-210.

Álvarez PeláEZ, R., (1998), «Eugenesia y fascismo en la España de los años treinta», en Ciencia y fascismo, Rafael Huertas y Carmen Ortiz, eds., Aranjuez, Doce Calles, pp 77-95.

FERRÁNDIZ, A. (1988), Aproximación psicológica a Marañón: su biografía y su bibliografía. Madrid: Ministerio de Cultura.

Gómez SANTOS, M. (1971), Vida de Gregorio Marañón. Madrid: Taurus.

HARO, F. (1932), Eugenesia y matrimonio. Madrid: Javier Morata.

LAÍN, P. (1969), Gregorio Marañón: Vida, obra y persona. Madrid: Espasa-Calpe.

MARAÑón, G. (1920), «Biología y feminismo», en Obras Completas, III. Madrid: EspasaCalpe, 1972 (20 ed.).

MARAÑón, G. (1925), «Sexo, trabajo y deporte» en Obras Completas, III. Madrid: Espasa-Calpe, 1972 (20 ed.).

MARAÑón, G. (1927), «Amor, conveniencia y eugenesia», en Obras Completas, III. Madrid: Espasa-Calpe, 1972 (20 ed.).

MARAÑón, G. (1927), «El deber de las edades», en Obras Completas, III. Madrid: EspasaCalpe, 1972 (20 ed).

MARAÑóN, G. (1929), «Breve prólogo sobre los prólogos y sobre la pasión provechosa», en Obras Completas, I. Madrid: Espasa-Calpe, 1966.

MARAÑón, G. (1931), «Amor y eugenesia», en Obras Completas, VIII. Madrid: EspasaCalpe, 1972.

MARAÑóN, G. (1931), «Eugenesia y moral», en Obras Completas, I. Madrid: EspasaCalpe, 1966.

MARAÑón, G. (1933), Raíz y decoro de España. Madrid: Espasa-Calpe

MARAÑóN, G. (1933), «Relación de la eugenesia con la mortalidad infantil», en Obras Completas, III. Madrid: Espasa-Calpe, 1972 (20 ed.).

MARAÑóN, G. (1939), «El pánico del instinto», en Obras Completas, IX. Madrid: EspasaCalpe, 1973.

MARAÑóN, G. (1947), Ensayos liberales. Madrid: Espasa-Calpe (20 ed.).

MARAÑón, G. (1951), «Ensayos sobre la vida sexual», en Obras Completas, VIII. Madrid: Espasa-Calpe, 1972.

Noguera, E. (1934): «Cómo se yuguló la generosa idea del Primer Curso Eugénico Español», en E. Noguera y L. Huerta, Genética, Eugenesia y Pedagogía Sexual. Libro de las Primeras Jornadas Eugénicas Españolas, vol 2.

Noguera, E. y HuERTA, L. (eds.) (1934), Genética, Eugenesia y Pedagogía sexual. Libro de las Primeras Jornadas Eugénicas Españolas (2 vols.). Madrid, Javier Morata

PÉREZ DE AYALA, R. (1923/1969), Las novelas de Urbano y Simona. Madrid, Alianza.

RODRÍGUEZ LAFORA, G. (1933), La educación sexual y la reforma de la moral sexual. Madrid, Revista de Pedagogía.

SÁNCHEZ GRANJEL, L. (1960), Gregorio Marañón: su vida y su obra. Madrid: Guadarrama.

TORRUBIANO, J. (1930), Al servicio del matrimonio. Teología y Eugenesia. Madrid: Javier Morata. 